\title{
Pengaruh Motivasi Kerja, Manajemen Pengetahuan dan Dukungan Organisasi Terhadap Kinerja Karyawan Hotel Chanti Semarang
}

\author{
Lusy diah*1, Krisnawati Setyaningrum Nugraheni ${ }^{2}$ \\ Sekolah Tinggi Ilmu Ekonomi Pariwisata, Indonesia ${ }^{1,2}$ \\ Email: krisnawatisetyaningrum@stiepari.ac.id
}

\begin{abstract}
This study aims to analyze the effect of work motivation, knowledge management and organizational support on employee performance at Hotel Chanti Semarang. This research uses quantitative descriptive which describes factual conditions with data collected from questionnaires based on direct observation of objects and interviews. Population and sample in this study were 64 employees of Hotel Chanti Semarang. Descriptive analysis through frequency and percentage, as well as statistical analysis using Multiple Linear Regression. The findings of this study, namely Work Motivation, Knowledge Management, and Organizational Support have been applied by employees and have had a positive and significant influence both simultaneously and partially on the performance of employees of Hotel Chanti Semarang. The results of the analysis show that all observed variables in the form of Work Motivation, Knowledge Management and Organizational Support are significant based on the acquisition of tcount $>$ ttable, and it is found that the dominant influence of Organizational Support (X3) affects the Employee Performance of Chanti Hotel Semarang.
\end{abstract}

Keywords: Work Motivation, Knowledge Management, Organizational Support, Employee Performance.

\begin{abstract}
Abstrak
Penelitian ini bertujuan untuk menganalisis pengaruh motivasi kerja, manajemen pengetahuan dan dukungan organisasi terhadap kinerja karyawan pada Hotel Chanti Semarang. Penelitan ini menggunakan deskriptif kuantitatif yang mendeskripsikan kondisi faktual dengan data - data yang terkumpul dari kuesioner berdasarkan pengamatan langsung objek dan wawancara. Populasi dan Sampel dalam penelitian ini adalah karyawan Hotel Chanti Semarang yang berjumlah 64 orang. Analisis secara deskriptif melalui frekuensi dan presentase, serta analisis secara statistik menggunakan Regresi Linear Berganda. Temuan penelitian ini yaitu motivasi kerja, manajemen pengetahuan, dan dukungan organisasi telah diterapkan karyawan dan memberikan pengaruh positif dan signifikan baik secara simultan maupun parsial terhadap kinerja karyawan Hotel Chanti Semarang. Hasil analisis menunjukkan keseluruhan variabel yang diamati berupa Motivasi Kerja, Manajemen Pengetahuan dan Dukungan Organisasi adalah signifikan berdasarkan perolehan nilai thitung > ttabel, dan ditemukan pengaruh Dukungan Organisasi (X3) yang dominan berpengaruh terhadap Kinerja Karyawan Hotel Chanti Semarang.
\end{abstract}

Kata Kunci: Motivasi Kerja, Manajemen Pengetahuan, Dukungan Organisasi, Kinerja Karyawan.

\section{A. PENDAHULUAN}

Perkembangan jasa perhotelan saat ini sedang mengalami persaingan yang sangat ketat, seiring meningkatnya perkembangan layanan jasa perhotelan yang dari tahun ke tahun semakin meningkat. Persaingan dapat dilihat dari kualitas, pelayanan, harga dan cara promosi pada masing - masing perusahaan. Menurut Zarkowi \& Widiartanto (2016) menyatakan bahwa "Persaingan semakin ketat, maka membutuhkan perubahan paradigma yang awalnya berbasis sumber daya (resource - based) menjadi berbasis pengetahuan (knowledge - based) yang bertumpu pada bidang analisis ilmu pengetahuan dan disertai dengan peningkatan sumber daya manusia". Di era kompetisi saat ini diharapkan para pelaku usaha dapat mendorong usahanya agar semakin kokoh dalam membangun

* Corresponding author

Received: July 02, 2021; Revised: July 27, 2021; Accepted: July 29, 2021 
kemampuan bersaingnya bukan hanya tingkat dosmetik, tetapi regional maupun global, karena akan muncul layanan - layanan kompetitif yang sangat terjangkau dengan harga dan kualitas yang baik.

Menurut Putra (2013) menambahkan bahwa "Motivasi karyawan merupakan salah satu strategi untuk meningkatkan kinerja karyawan". Suatu perusahaan akan dituntut untuk memiliki produktivitas yang baik agar dapat mencapai target yang sudah ditentukan oleh perusahaan. Karyawan harus memiliki pengetahuan dan sikap dalam berkomunikasi, sehingga pergeseran paradigma akan membawa potensi dalam menggerakkan perusahaan dengan bertumbuhnya kesadaran dari pelaku bisnis tentang aset pengetahuan. Manajemen pengetahuan merupakan aspek penting dalam sebuah perusahaan, agar dapat berjalan secara efektif dan stabil. Menurut Iskandar \& Subekan (2018) menyebutkan bahwa "Pengetahuan ada dua jenis, yaitu pengetahuan terbatinkan (tacit knowledge) dan pengetahuan sudah terekam yang termodifikasi dalam dokumen (explicit knowledge)". Penerapan manajemen pengetahuan dalam dunia bisnis dapat meningkatkan kinerja sumber daya manusia dengan melalui penilaian karyawan.

Menurut Hayati (2020) menyatakan bahwa "Dukungan Organisasi didefinisikan sebagai sejauh mana pegawai percaya bahwa organisasi dapat menghargai kontribusi mereka dan peduli terhadap kesejahteraan mereka". Jika karyawan menganggap bahwa dukungan organisasi yang diterimanya tinggi, maka karyawan tersebut akan menyatukan keanggotaannya sebagai anggota organisasi ke dalam identitas dirinya dan akan mengembangkan hubungan persepsi yang lebih positif terhadap organisasi. Menurut Hayati (2020) menyatakan bahwa "Komitmen diatas akan mendorong karyawan untuk membantu organisasi dalam mencapai tujuannya, dan dapat meningkatkan harapan bahwa performa kerja akan diperhatikan dan dihargai oleh organisasi".

Visi dan misi suatu perusahaan akan tercapai apabila perusahaan dapat meningkatkan kinerja karyawan mereka. Menurut Putra (2013) menyatakan bahwa "Baik buruknya kondisi kinerja perusahaan akan mempengaruhi tercapainya keuntungan perusahaan". Menurut Tina Febriani \& Desi Indrawati (2013) menyatakan bahwa "Dalam dunia usaha yang berkompetensi secara global, maka perusahaan akan memerlukan kinerja karyawan yang tinggi". Karyawan berhak mendapatkan umpan balik atas kinerja yang telah mereka berikan terhadap perusahaan. Menurut Nugroho (2013) menyatakan bahwa "Kinerja (performance) yang berarti prestasi kerja, pelaksanaan kerja, dan pencapaian kerja. Kinerja sangat penting untuk organisasi karena kinerja karyawan yang mengarahkan bisnis menuju arah yang lebih sukses".

Menurut Miskiani \& Bagia (2021) menyatakan bahwa "Sumber daya manusia mempunyai peranan penting dalam suatu organisasi, oleh sebab itu sumber daya manusia sebagai penentu tujuan organisasi, tanpa peran manusia secanggih apapun teknologi yang dimiliki oleh organisasi maka hal tersebut tidak ada manfaatnya jika tidak digerakkan oleh tenaga manusia". Keberhasilan suatu perusahaan akan dipengaruhi oleh sumber daya manusia yang unggul agar dapat memudahkan perusahaan dalam bersaing di dunia bisnis saat ini.

Permasalahan tentang kinerja karyawan dapat dijumpai di berbagai perusahaan, salah satunya di Hotel Chanti Semarang, kurangnya dorongan dalam diri karyawan dapat menyebabkan karyawan tidak maksimal dalam bekerja. Maka diperlukan motivasi kerja, manajemen pengetahuan dan dukungan organisasi agar dapat membangkitkan semangat karyawan dalam bekerja. Dalam hal pengetahuan pribadi, karyawan tidak menerapkan pengalaman yang mereka miliki, dan cenderung mengabaikan pengalaman yang mereka dapatkan selama bekerja. Padahal pengalaman tersebut dapat meningkatkan pengetahuan, kemampuan dan mendukung kinerja mereka. Rumusan masalah tersebut sebagai berikut 1. Bagaimana motivasi kerja berpengaruh terhadap kinerja karyawan Hotel Chanti Semarang ? 2. Bagaimana manajemen pengetahuan berpengaruh terhadap kinerja karyawan Hotel Chanti Semarang ? 3. Bagaimana dukungan organisasi berpengaruh terhadap kinerja karyawan Hotel Chanti Semarang ? 4. 
Bagaimana motivasi kerja, manajemen pengetahuan dan dukungan organisasi berpengaruh terhadap kinerja karyawan Hotel Chanti Semarang ? 5.Variabel manakah yang paling berpengaruh terhadap kinerja karyawan Hotel Chanti Semarang ?

\section{B. METODE PENELITIAN}

Metode penelitian yang digunakan adalah metode penelitian kuantitatif, faktual dan aktual dengan membuat angket kepada responden yang akan menjawab pertanyaan tentang pengaruh motivasi kerja, manajemen pengetahuan dan dukungan organisasi terhadap kinerja karyawan Hotel Chanti Semarang. Jumlah populasi dan sampel dalam penelitian ini adalah 64 orangyang merupakan karyawan Hotel Chanti Semarang. Uji validitas adalah suatu ukuran yang menunjukan tingkat - tingkat kevalidan suatu instrumen (Mahendra, 2015) sedangkan uji reliabilitas adalah derajat konsistensi dan stabilitas data dalam interval waktu tertentu (Mahendra, 2015). Teknik pengumpulan data menggunakan teknik kuesioner dengan membuat serangkaian pernyataan yang terkait dengan Motivasi Kerja, Manajemen Pengetahuan, Dukungan Organisasi dan Kinerja Karyawan. Sedangkan skala pengukuran menggunakan skala Likert, dengan pilihan kategori : Sangat setuju (SS), Setuju (S), Kurang setuju (KS), Tidak setuju (TS), Sangat tidak setuju (STS). Adapun rumus persamaan Linear Berganda :

$$
y=a+b_{1} x_{1}+b_{2} x_{2}+b_{3} x_{3}+e
$$

Keterangan : $\quad y$

$$
\text { = Kinerja Karyawan (variabel dependen) }
$$

a $\quad=$ konstanta persamaan regresi

$\mathrm{b}_{1} \mathrm{~b}_{2} \mathrm{~b}_{3} \quad=$ Koefisien Regresi Parsial

$\mathrm{x}_{1} \quad=$ Motivasi Kerja

$\mathrm{x}_{2} \quad=$ Manajemen Pengetahuan

$\mathrm{x}_{3} \quad=$ Dukungan Organisasi

e $\quad$ error

\section{HASIL DAN ANALISIS}

1. Deskripsi Responden

Tabel 1. Identitas responden berdasarkan jenis kelamin

\begin{tabular}{|c|l|c|c|}
\hline No. & Jenis Kelamin & Jumlah (Responden) & Presentase (\%) \\
\hline 1. & Laki - Laki & 48 & $75 \%$ \\
\hline 2. & Perempuan & 16 & $25 \%$ \\
\hline \multicolumn{2}{|l}{ Jumlah } & 64 & $100 \%$ \\
\hline
\end{tabular}

Sumber : Data Primer diolah 2021

Dari data karakteristik responden berdasarkan jenis kelamin pada tabel 1, maka jumlah responden terbesar adalah laki - laki yaitu sebanyak 48 responden atau (75\%), sedangkan jumlah responden terendah adalah responden yang berjenis kelamin perempuan sebanyak 16 responden atau (25\%). Maka dapat disimpulkan bahwa sebagian besar responden berjenis kelamin laki - laki.

Tabel 2 Identitas responden berdasarkan usia

\begin{tabular}{|l|l|l|l|}
\hline No. & Umur Responden & Jumlah (Responden) & Presentase (\%) \\
\hline 1. & $<30$ th & 29 & $45,3 \%$ \\
\hline 2. & $31-40$ th & 16 & $25,0 \%$ \\
\hline 3. & $41-50$ th & 19 & $29,7 \%$ \\
\hline Jumlah & 64 & $100 \%$ \\
\hline
\end{tabular}


Sumber : Data Primer diolah 2021

Dari data karakteristik responden berdasarkan usia pada tabel 2 diatas, maka jumlah responden terbesar dengan kategori umur $<30$ th sebanyak 29 responden atau (45,3\%), umur $41-50$ th sebanyak 19 responden atau $(29,7 \%)$ dan umur $31-40$ th sebanyak 16 responden atau $(25,0 \%)$. Maka dapat disimpulkan bahwa sebagian besar responden berusia $<30$ th.

Tabel 3 Identitas responden berdasarkan tingkat pendidikan

\begin{tabular}{|l|l|l|l|}
\hline No. & Tingkat Pendidikan & Jumlah (Responden) & Presentase (\%) \\
\hline 1. & SMA/SMK & 14 & $21,9 \%$ \\
\hline 2. & D1 & 7 & $10,9 \%$ \\
\hline 3. & D3 & 21 & $32,8 \%$ \\
\hline 4. & S1 & 22 & $34,4 \%$ \\
\hline Jumlah & 64 & $100 \%$ \\
\hline
\end{tabular}

Sumber : Data Primer diolah 2021

Dari data karakteristik responden berdasarkan tingkat pendidikan pada tabel 3, maka jumlah responden terbesar dengan kategori pendidikan S1 sebanyak 22 responden atau $(34,4 \%)$, pendidikan D3 sebanyak 21 responden atau (32,8\%), pendidikan SMA/SMK sebanyak 14 responden atau (21,9\%), dan pendidikan D1 sebanyak 7 responden atau $(10,9 \%)$. Maka dapat disimpulkan bahwa sebagian besar responden berpendidikan terakhir $\mathrm{S} 1$.

\section{Uji Validitas dan Uji Reabilitas}

Pengumpulan data dari kuesioner dibagikan kepada 64 responden di Hotel Chanti Semarang, dan data tersebut kemudian di olah di dalam program SPSS (Statistical Product and Service Solution) untuk membuktikan keabsahan data melalui uji validitas dan reliabilitas. Uji validitas pada penelitian ini menggunakan korelasi Product Moment Person, yaitu dengan tingkat nilai r tabel sebesar $5 \%(0,05)$. Hasil olah data uji validitas ini menggunakan SPSS dengan jawaban pada tabel berikut ini :

Tabel 4 Hasil Uji Validitas

\begin{tabular}{|l|l|l|l|l|}
\hline Variabel & Indikator & $\begin{array}{l}\text { Person Correlation }(\mathrm{r} \\
\text { hitung) }\end{array}$ & $\begin{array}{l}\mathrm{Df}=\mathrm{N} 2 \\
\mathrm{r} \text { tabel }\end{array}$ & Keterangan \\
\hline Motivasi Kerja $\left(\mathrm{X}_{1}\right)$ & 1 & 0,659 & 0,2075 & Valid \\
\cline { 2 - 5 } & 2 & 0,763 & 0,2075 & Valid \\
\cline { 2 - 5 } & 3 & 0,793 & 0,2075 & Valid \\
\cline { 2 - 5 } & 4 & 0,679 & 0,2075 & Valid \\
\hline \multirow{3}{*}{$\begin{array}{l}\text { Manajemen } \\
\text { Pengetahuan }\left(\mathrm{X}_{2}\right)\end{array}$} & 1 & 0,655 & 0,2075 & Valid \\
\cline { 2 - 5 } & 2 & 0,818 & 0,2075 & Valid \\
\cline { 2 - 5 } & 3 & 0,681 & 0,2075 & Valid \\
\cline { 2 - 5 } & 4 & 0,737 & 0,2075 & Valid \\
\hline \multirow{3}{*}{$\begin{array}{l}\text { Orgunganisasi }\left(\mathrm{X}_{3}\right) \\
\text { Kinerja Karyawalid }\end{array}$} & 1 & 0,746 & 0,2075 & Valid \\
\cline { 2 - 5 } (Y) & 2 & 0,835 & 0,2075 & Valid \\
\cline { 2 - 5 } & 3 & 0,687 & 0,2075 & Valid \\
\cline { 2 - 5 } & 4 & 0,759 & 0,2075 & Valid \\
\cline { 2 - 5 } & 2 & 0,606 & 0,2075 & Valid \\
\cline { 2 - 5 } & 3 & 0,640 & 0,2075 & Valid \\
\cline { 2 - 5 } & 4 & 0,651 & 0,2075 & Valid \\
\cline { 2 - 5 } & 5 & 0,647 & 0,2075 & \\
\cline { 2 - 5 } & 6 & 0,650 & 0,2075 & \\
\hline
\end{tabular}


Sumber : Data Primer diolah 2021

Berdasarkan tabel 4 menunjukkan bahwa nialai $r$ hitung setiap indikator lebih besar dari $r$ tabel = $0,2075(\mathrm{~N}-2=64-2=62$, sig 0,05) yang berarti indikator - indikator tersebut dinyatakan valid. Uji reabilitas ini dilakukan dengan bantuan program spss dengan Cronbach Alpha sebesar 0,60 dengan ketentuan apabila Cronbach Alpha > 0,60 maka suatu variabel dinyatakan reliable. Apabila Cronbach Alpha $<0,60$ maka suatu variabel dinyatakan tidak reliabel.

Tabel 5 Hasil Uji Reabilitas

\begin{tabular}{|l|l|l|l|l|}
\hline \multicolumn{1}{|c|}{ Variabel } & \multicolumn{1}{c|}{ Cronbach Alpha } & \multicolumn{1}{c|}{$>$} & \multicolumn{1}{c|}{ Ketetapan } & Keterangan \\
\hline Motivasi Kerja $\left(\mathrm{X}_{1}\right)$ & 0,699 & $>$ & 0,60 & Reliabel \\
\hline $\begin{array}{l}\text { Manajemen } \\
\text { Pengetahuan }\left(\mathrm{X}_{2}\right)\end{array}$ & 0,698 & $>$ & 0,60 & Reliabel \\
\hline $\begin{array}{l}\text { Dukungan Organisasi } \\
\left(\mathrm{X}_{3}\right)\end{array}$ & 0,749 & $>$ & 0,60 & Realiabel \\
\hline Kinerja Karyawan $(\mathrm{Y})$ & 0,716 & $>$ & 0,60 & Realiabel \\
\hline
\end{tabular}

Sumber : Data Primer diolah 2021

Berdasarkan tabel 5 hasil uji reabilitas dapat disimpulkan bahwa variabel - variabel yang digunakan dalam penelitian ini adalah reliabel, karena setiap variabel memiliki nilai Alpha Cronbach > 0,60 .

\section{Pengujian Hipotesis}

Tabel 6 Hasil Analisis Regresi Linear Berganda

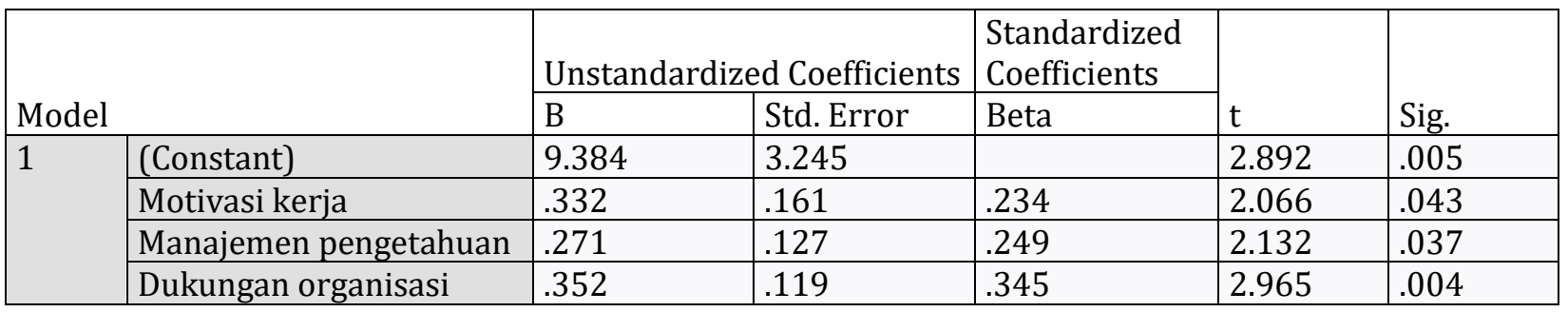

Sumber : Output SPSS 2021

Maka berdasarkan tabel persamaan regresi linear berganda yang diperoleh adalah sebagai berikut: $y=9,384+0,332 x_{1}+0,271 x_{2}+0,352 x_{3}+e$

Dari persamaan tersebut diperoleh keterangan sebagai berikut :

1. Nilai konstanta sebesar 9,384 menunjukkan bahwa variabel - variabel independen (Motivasi Kerja, Manajemen Pengetahuan dan Dukungan Organisasi) diasumsikan konstan (0). Maka variabel dependen (Kinerja Karyawan) yaitu sebesar 9,384.

2. Koefisien variabel Motivasi Kerja sebesar 0,332 berarti setiap kenaikan motivasi kerja sebesar 1 poin, maka kinerja karyawan akan naik sebesar 0,332 dengan asumsi variabel lain tetap.

3. Koefisien variabel Manajemen Pengetahuan sebesar 0,271 berarti setiap kenaikan manajemen pengetahuan sebesar 1 poin, maka kinerja karyawan akan naik sebesar 0,271 dengan asumsi variabel lain tetap.

4. Koefisien variabel Dukungan Organisasi sebesar 0,352 berarti setiap kenaikan dukungan organisasi sebesar 1 poin, maka kinerja karyawan akan naik sebesar 0,352 dengan asumsi variabel lain tetap. 
Tabel 7 Hasil Uji t

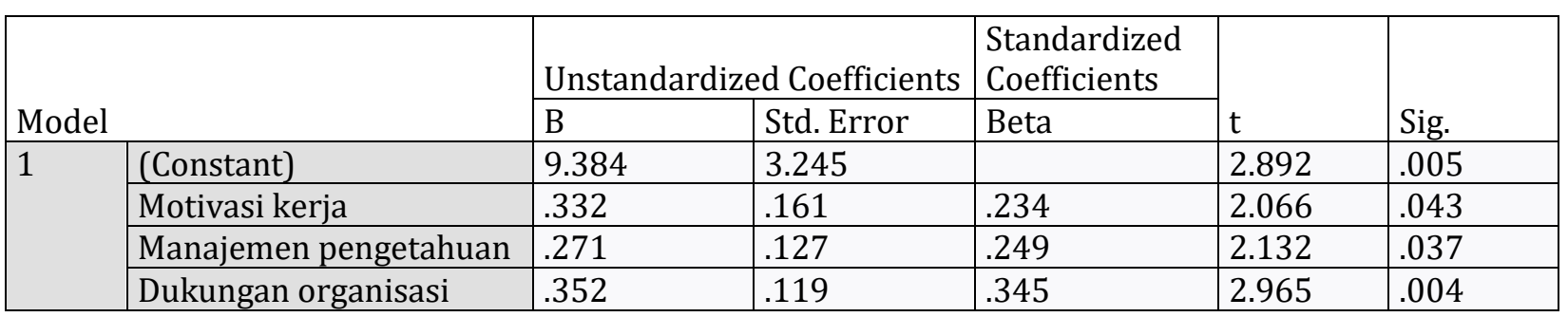

Sumber : Output SPSS 2021

Hasil dari uji t berdasarkan tabel 7 dapat disimpulkan sebagai berikut :

1. Hipotesis $1\left(\mathrm{H}_{1}\right)$ yang menyatakan bahwa motivasi kerja berpengaruh signifikan terhadap kinerja karyawan diterima, karena nilai signifikan yang diperoleh lebih kecil dari 0,05 yaitu $0,043<0,05$.

2. Hipotesis $2\left(\mathrm{H}_{2}\right)$ yang menyatakan bahwa manajemen pengetahauan berpengaruh signifikan terhadap kinerja karyawan diterima, karena nilai signifikan yang diperoleh lebih kecil dari 0,05 yaitu $0,037<0,05$.

3. Hipotesis $3\left(\mathrm{H}_{3}\right)$ yang menyatakan bahwa dukungan organisasi berpengaruh signifikan terhadap kinerja karyawan diterima, karena nilai signifikan yang diperoleh lebih kecil dari 0,05 yaitu $0,004<0,05$.

4. $\quad$ Uji F

\section{Tabel 8 Uji F}

ANOVA $^{\mathrm{a}}$

\begin{tabular}{|c|c|c|c|c|c|c|}
\hline \multicolumn{2}{|c|}{ Model } & $\begin{array}{ll}\text { Sum } & \text { of } \\
\text { Squares }\end{array}$ & Df & Mean Square & $\mathrm{F}$ & Sig. \\
\hline \multirow[t]{3}{*}{1} & Regression & 86.950 & 3 & 28.983 & 8.089 & $.000^{\mathrm{b}}$ \\
\hline & Residual & 214.987 & 60 & 3.583 & & \\
\hline & Total & 301.938 & 63 & & & \\
\hline
\end{tabular}

Sumber : Output SPSS 2021

Berdasarkan tabel 8 diatas terlihat bahwa nilai $\mathrm{F}$ hitung sebesar 8.089 dengan nilai signifikasi 0,000 . Nilai signifikan $0.000<0,05$ maka dapat disimpulkan bahwa model regresi dalam penelitian ini merupakan model yang fit atau diterima.

\section{Koefisien Determinasi $\left(R^{2}\right)$}

Tabel 9 Hasil Uji Koefisien Determinasi

\section{Model Summary}

\begin{tabular}{|l|l|l|l|l|}
\hline Model & R & R Square & $\begin{array}{l}\text { Adjusted R } \\
\text { Square }\end{array}$ & $\begin{array}{l}\text { Std. Error of } \\
\text { the Estimate }\end{array}$ \\
\hline 1 & $.537^{\mathrm{a}}$ & .288 & .252 & 1.893 \\
\hline
\end{tabular}

Sumber : Output SPSS 2021

Dari tabel 9 angka koefisien Determinasi ( $\left.\mathrm{R}^{2}\right)$ sebesar 0,252 ini berarti bahwa motivasi kerja, manajemen pengetahuan dan dukungan organisasi mempunyai peranan $25,2 \%$ secara bersama - sama 
untuk dapat menjelaskan atau menerangkan variabel kinerja karyawan. Sedangkan sisanya 74,5 \% (100 $\%$ - 25,2 \%) dijelaskan oleh variabel lain yang mempengaruhi kinerja karyawan.

\section{Pembahasan}

\section{Pengaruh Motivasi Kerja Terhadap Kinerja Karyawan}

Berdasarkan hasil penelitian uji hipotesis yang pertama menunjukkan bahwa motivasi kerja berpengaruh signifikan terhadap kinerja karyawan karena motivasi kerja memiliki nilai koefisien positif sebesar 2,066 dan nilai signifikan sebesar 0,043. Hal ini telah sesuai dengan penelitian yang di lakukan oleh Muliharta (2015) menyatakan bahwa motivasi kerja berpengaruh positif dan signifikan terhadap kinerja karyawan. Motivasi kerja berperan sebagai pendorong agar karyawan lebih giat dalam bekerja. Apabila pimpinan memberikan motivasi kerja yang positif, maka karyawan akan merasa senang dan dihargai dalam bekerja.

Menurut Pamulang (2021) motivasi adalah dorongan untuk menggerakkan sebuah potensi sumber daya manusia agar mau bekerja untuk melakukan suatu pekerjaan yang berlangsung secara sadar. Berdasarkan pengertian diatas diharapkan Hotel Chanti Semarang dapat memberikan motivasi, agar kinerja karyawan akan lebih meningkat. Motivasi sebagai variabel penting, karena kinerja karyawan yang dihasilkan baik maupun buruk tergantung dari motivasi yang diterima oleh karyawan.

\section{Pengaruh Manajemen Pengetahuan Terhadap Kinerja Karyawan}

Berdasarkan hasil penelitian uji hipotesis yang kedua menunjukkan bahwa manajemen pengetahuan berpengaruh signifikan terhadap kinerja karyawan karena manajemen pengetahuan memiliki nilai koefisien positif sebesar 2,132 dan nilai signifikan sebesar 0,037. Hal ini telah sesuai dengan penelitian yang di lakukan oleh Zarkowi \& Widiartanto (2016) bahwa semakin kuat dukungan manajemen pengetahuan yang dimiliki oleh karyawan maka akan semakin mempengaruhi meningkatnya kinerja karyawan.

Menurut Oktavian (2021) Manajemen Pengetahuan dipandang penting dalam rangka mentransfer pengetahuan, keterampilan dan perilaku kerja efektif. Berdasarkan pengertian diatas diharapkan Hotel Chanti Semarang dapat memberikan manajemen pengetahuan yang sesuai, agar kinerja karyawan akan lebih meningkat. Kinerja karyawan yang dihasilkan baik maupun buruk tergantung dari manajemen pengetahuan yang diberikan kepada karyawan.

\section{Pengaruh Dukungan Organisasi Terhadap Kinerja Karyawan}

Berdasarkan hasil penelitian uji hipotesis yang ketiga menunjukkan bahwa manajemen pengetahuan berpengaruh signifikan terhadap kinerja karyawan karena manajemen pengetahuan memiliki nilai koefisien positif sebesar 2,965 dan nilai signifikan sebesar 0,004. Hal ini telah sesuai dengan penelitian terdahulu yang dilakukan oleh Dana \& Dewi (2016) menyatakan bahwa dukungan organisasi memiliki pengaruh signifikan terhadap kinerja karyawan. Semakin besar dukungan organisasi yang diberikan, maka akan semakin baik kinerja yang dihasilkan oleh karyawan.

Fata (2020) dukungan organisasi merupakan kesiapan organisasi dalam menghargai peningkatan kinerja, dan mengembangkan keyakinan karyawan secara global bahwa sejauh mana organisasi menghargai kontribusi dan kepedulian tentang kesejahteraan karyawan. Berdasarkan pengertian diatas diharapkan Hotel Chanti Semarang dapat memberikan dukungan organisasi yang sesuai, agar kinerja karyawan mereka lebih meningkat. Kinerja karyawan yang dihasilkan baik maupun buruk tergantung dari dukungan organisasi yang diberikan oleh pihak manajemen. 


\section{Pengaruh Motivasi Kerja, Manajemen Pengetahuan dan Dukungan Organisasi Terhadap Kinerja Karyawan}

Berdasarkan hasil penelitian uji hipotesis yang keempat menunjukkan bahwa ada pengaruh positif dari variabel motivasi kerja, manajemen pengetahuan dan dukungan organisasi terhadap kinerja karyawan dimana nilai $\mathrm{F}$ sebesar 8,089 yaitu dengan tingkat signifikasi 0,000 dimana nilai signifikan ini lebih kecil dari 0,005 sehingga hipotesis keempat yang diajukan ada pengaruh positif dan signifikan antara motivasi kerja, manajemen pengetahuan dan dukungan organisasi secara bersama - sama kepada kinerja karyawan dapat diterima. Hal ini dikarenakan karyawan merasa motivasi kerja, manajemen pengetahuan dan dukungan organisasi yang diberikan oleh pihak manajemen hotel sudah cukup baik. Menurut Rozalia (2015) Kinerja Karyawan adalah hasil kerja yang diraih oleh seseorang dalam melaksanakan tugas kerja yang diberikan kepadanya. Oleh karena itu pihak manajemen hotel harus memberikan motivasi kerja, manajemen pengetahuan dan dukungan organisasi agar karyawan melakukan pekerjaannya sesuai dengan SOP dan alur yang diberikan.

\section{Variabel Yang Paling Berpengaruh Terhadap Kinerja Karyawan}

Dari tiga variabel independen atau bebas yang diteliti, variabel Dukungan Organisasi memiliki pengaruh paling signifikan dengan nilai beta standar 0,345 dimana nilai ini lebih besar dibandingkan dengan variabel Motivasi Kerja dan Manajemen Pengetahuan. Sehingga dapat diambil kesimpulan bahwa Dukungan Organisasi yang paling berpengaruh terhadap Kinerja Karyawan di Hotel Chanti Semarang.

\section{E. SIMPULAN}

Ada pengaruh positif dan signifikan variabel Motivasi Kerja terhadap Kinerja Karyawan di Hotel Chanti Semarang, sehingga hipotesis pertama diterima. Ada pengaruh positif dan signifikan variabel Manajemen Pengetahuan terhadap Kinerja Karyawan di Hotel Chanti Semarang, sehingga hipotesis kedua diterima. Ada pengaruh positif dan signifikan variabel Dukungan Organisasi terhadap Kinerja Karyawan di Hotel Chanti Semarang, sehingga hipotesis ketiga diterima. Ada pengaruh positif dan signifikan variabel Motivasi Kerja, Manajemen Pengetahuan, dan Dukungan Organisasi terhadap Kinerja Karyawan di Hotel Chanti Semarang, sehingga hipotesis keempat diterima.

Variabel Dukungan Organisasi lebih berpengaruh dibanding variabel Motivasi Kerja dan Manajemen Pengetahuan terhadap Kinerja Karyawan di Hotel Chanti Semarang, sehingga hipotesis kelima dapat diterima.

\section{Daftar Referensi}

Abdurrohman, S. 2021. (n.d.). Pengaruh budaya organisasi terhadap efektivitas manajemen pengetahuan di disperkim pemprov jabar. 2 .

Abor, J., \& Bokpin, G. A. (2010). Investment opportunities, corporate finance, and dividend payout policy. Studies in Economics and Finance, 27(3), 180-194. https://doi.org/10.1108/10867371011060018

Aizid, R. (2016). Biografi Ulama Nusantara. Diva Press.

Anwar, R., Darmawan, D., \& Setiawan, C. (2016). Kajian Kitab Tafsir dalam Jaringan Pesantren di Jawa Barat. Wawasan: Jurnal Ilmiah Agama Dan Sosial Budaya, 1(1), 56-69. https://doi.org/10.15575/jw.v1i1.578

Arifandi, M., \& Presilawati, S.E., M.M, F. (2020). Pengaruh Personal Knowledge,Job Procedure Dan Technology Terhadap Kinerja Pegawai Pada Dinas Sosial Aceh. Jurnal Ilmiah Manajemen Muhammadiyah Aceh, 9(2), 133-168. https://doi.org/10.37598/jimma.v9i2.814

Cretu, A. E., \& Brodie, R. J. (2007). The influence of brand image and company reputation where manufacturers market to small firms: A customer value perspective. Industrial Marketing 
Management, 36(2), 230-240. https://doi.org/10.1016/j.indmarman.2005.08.013

Dana, N., \& Dewi, A. (2016). Pengaruh Kompensasi Dan Dukungan Organisasi Terhadap Kinerja Karyawan Di Hotel Asana Agung Putra Bali. None, 5(9), 254211.

Ekobelawati, F. (2001). PENGARUH KNOWLEDGE MANAGEMENT TERHADAP KINERJA KARYAWAN Fransiska Ekobelawati Akademi Sekretari Manajemen Indonesia Pontianak ( ASMI) Email: Sischasira06@Gmail.com.20-24.

Erawati, A. H. (2015). Pengaruh Lingkungan Kerja dan Motivasi Kerja terhadap Kinerja Karyawan di Hotel Aamaris Makassar. Jurnal Economix, 3(1), 82-93.

Fata, R. (2020). Pengaruh Dukungan Organisasi dan Kontrol Diri Terhadap Disiplin. Jurnal Psikologi, 16(2), 28-36.

Hadi, S. P., Bisnis, D. A., \& Diponegoro, U. (2019). PENGARUH MOTIVASI KERJA DAN PERSONAL KNOWLEDGE TERHADAP KINERJA KARYAWAN Pendahuluan Kerangka Teori. IX(Iv), 482-487.

Harianto, A. (2016). Pengaruh Motivasi Kerja Terhadap Komitmen Afektif Dengan Kepuasan Kerja Sebagai Variabel Mediator Di Hotel X. Kinerja, 20(2), 95. https://doi.org/10.24002/kinerja.v20i2.837

Hasyim, M. A. N., Maje, G. I. L., Alimah, V. ', \& Priyadi, S. A. P. (2020). Pengaruh Motivasi dan Disiplin Kerja Terhadap Kinerja Karyawan PT.Kahatex. Jesya (Jurnal Ekonomi \& Ekonomi Syariah), 3(2), 58-69. https://doi.org/10.36778/jesya.v3i2.161

Hayati, N. (2020). Pengaruh Persepsi Dukungan Organisasi Dan. Equilibrium: Jurnal Ekonomi Manajemen-Akuntansi, 16(2), 54-61.

Ihsan, M., Sari, V. N., \& Putra, R. A. (2021). Karyawan Dengan Gaya Kepemimpinan Sebagai Variabel Moderating Pada PT P\&P Lembahkaret. 4(2), 190-203.

Indarjanti, P., \& Bodroastuti, T. R. I. (2012). Pengaruh Kemampuan, Usaha Dan Dukungan Organisasi Terhadap Kinerja The Influence of Ability , Effort and Support of Organization to Employee's Performance. Kajian Akuntansi Dan Bisnis, 64-83. https://www.neliti.com/publications/102597/pengaruh-kemampuan-usaha-dandukungan-organisasi-terhadap-kinerja

Iskandar, A., \& Subekan, A. (2018). the Pengaruh Personal Knowledge, Job Procedure Dan Technology Terhadap Kinerja Pegawai Organisasi Publik. JRMSI - Jurnal Riset Manajemen Sains Indonesia, 9(2), 168-192. https://doi.org/10.21009/jrmsi.009.2.01

Jauvani, E. (2017). Pengaruh Stres Kerja Terhadap Kinerja Karyawan : Studi Kasus pada Tenaga. $4(1), 221-228$.

Jensen, M. C., \& Meckling, W. H. (1976). Theory of the firm: Managerial behavior, agency costs and ownership structure. Journal of Financial Economics, 3(4), 305-360. https://doi.org/10.1016/0304-405X(76)90026-X

Kandou, yunita lidya. (2016). PENGARUH KNOWLEDGE MANAGEMENT, SKILL DAN ATTITUDE TERHADAP KINERJA KARYAWAN ( STUDI PADA PT . BANK SULUTGO KANTOR PUSAT DI MANADO ). 16(01), 147-158.

Kartika, E. W., Kaihatu, T. S., Perhotelan, P. M., Ekonomi, F., \& Petra, U. K. (2010). Analisis Pengaruh Motivasi Kerja Terhadap Kepuasan Kerja (Studi Kasus pada Karyawan Restoran di Pakuwon Food Festival Surabaya). Jurnal Manajemen Dan Kewirausahaan (Journal of Management and Entrepreneurship), 12(1), 100-112. https://doi.org/10.9744/jmk.12.1.pp.100-112

Mahendra, I. (2015). Analisa Penerimaan Pengguna Sistem Inforasi Koperasi Pada Koperasi Karyawan Budi Setia Jakarta Dengan Technologi Acceptance Model. Jurnal Pilar Nusa Mandiri, $X I(1), 70-80$.

Miskiani, K. A., \& Bagia, I. W. (2021). Peningkatan Kinerja Karyawan Melalui Motivasi Kerja. 2(2), 120-129.

Mujiasih, E. (2015). Hubungan Antara Persepsi Dukungan Organisasi (Perceived Organizational Support) Dengan Keterikatan Karyawan. Jurnal Psikologi Undip, 14(1), 40-51. https://doi.org/10.14710/jpu.14.1.40-51

Muliharta, K. (2015). Pengaruh Kemampuan kerja dan motivasi kerja terhadap kinerja karyawan pada hotel Puri Bugis LovinaMuliharta, Ketut. Jurnal Jurusan Pendidikan Ekonomi (JIPE), 5(1), $1-14$.

Nugrahanto, A. D. (2015). Blusukan Dalam Sejarah : Dari Sambernyawa sampai Jokowi. Kompasiana. 
Nugroho, A., Tanoyo, K., \& Yudha w., T. (2013). Pengaruh Lingkungan Kerja Terhadap Kinerja Karyawan Hotel Majapahit Surabaya. Journal of Chemical Information and Modeling, 53(9), 1689-1699.

Oktavian, A., Prasetia, A., Masnun, M., \& Widoro, W. (2021). Pengaruh Pelatihan dan Berbagi Pengetahuan Terhadap Kinerja Karyawan Melalui Pengetahuan Manajemen. MASTER: Jurnal Manajemen Strategik Kewirausahaan, 1(1), 69-78. https://doi.org/10.37366/master.v1i1.132

Pamulang, U. (2021). Konsepsi motivasi kerja dalam upaya meningkatkan kinerja karyawan. 4(1), $11-20$

Putra, G. (2013). Pengaruh Disiplin Kerja, Gaya Kepemimpinan, Dan Motivasi Kerja Terhadap Kinerja Karyawan Pada Hotel Matahari Terbit Bali, Tanjung Benoa-Nusa Dua. E-Jurnal Manajemen Universitas Udayana, 2(7), 253493.

Rahmawati, R., Yahiji, K., \& Rusli, M. (2019). Mopo'alati Tradition In The Coastal Muslim Community At Molotabu Beach Bone Bolango District. Wawasan: Jurnal Ilmiah Agama Dan Sosial Budaya, 4(1), 65-79. https://doi.org/10.15575/jw.v4i1.4080

Retnoningsih, E. (2013). Knowledge Management System (KMS) Dalam Meningkatkan Inovasi LPPM Perguruan Tinggi. Evolusi, I(1), 76-85.

Ross, S. A. (1977). The Determination of Financial Structure: The Incentive-Signalling Approach. The Bell Journal of Economics, 8(1), 23. https://doi.org/10.2307/3003485

Rozalia, N. (2015). PENGARUH MOTIVASI KERJA DAN DISIPLIN KERJA TERHADAP KINERJA KARYAWAN (Studi Kasus Pada Karyawan PT. Pattindo Malang). Jurnal Administrasi Bisnis S1 Universitas Brawijaya, 26(2), 86280.

Susmiati. (2015). Pengaruh Budaya Organisasi Dan Dukungan Organisasi Persepsian Terhadap Kinerja Karyawan Dengan Komitmen Organisasi Sebagai Variabel Intervening. Management Analysis Journal, 4(1), 79-87. https://doi.org/10.15294/maj.v4i1.7226

Tina Febriani, N., \& Desi Indrawati, A. (2013). Pengaruh Motivasi, Kompensasi, Serta Lingkungan Kerja Fisik Terhadap Kinerja Kerja Karyawan Hotel the Niche Bali. E-Jurnal Manajemen Universitas Udayana, 2(5), 254973.

Wijayanti, D. P., \& Sundiman, D. (2017). Pengaruh Knowledge Management Terhadap Kinerja Karyawan (Studi Empiris Pada Pt. Sms Kabupaten Kotawaringin Timur). DeReMa Jurnal Manajemen, 12(1), 69-85.

Zarkowi, R., \& Widiartanto. (2016). Pengaruh Personal Knowledge, Organizational Learning, Dan Teknologi Terhadap Kinerja Karyawan Hotel Patra Jasa Semarang. National Conference on ASBIS 2016, 1(1), 294-302. 